\title{
Respiratory mechanics after heart-lung and bilateral lung transplantation
}

\author{
R A Chacon, P A Corris, J H Dark, G J Gibson
}

\begin{abstract}
Background - The factors determining respiratory mechanics following heartlung transplantation (HLT) and bilateral lung transplantation (BLT) are incompletely understood.
\end{abstract}

Methods - The dynamic and static lung volumes of 15 patients after HLT $(n=6)$ and BLT $(n=9)$ with no evidence of obliterative bronchiolitis were analysed to assess the factors which determine lung volumes following transplantation. Posttransplantation total lung capacity (TLCpost) was compared with the size of the recipient's lungs (TLCpre), the predicted capacity of the thorax of the recipient (TLCpred), and the predicted size of the donor's lungs (TLCdon). In addition, the post-transplantation respiratory mechanics were investigated by measuring the static pressure-volume (PV) curve of the lungs and the maximum respiratory pressures in a subgroup of nine patients (four HLT, five BLT).

Results - TLCpost was closely related to TLCpred in both groups and showed no correlation with TLCpre. The mean $(95 \%$ CI) TLCpost was 102.5 (90.2 to 115$) \%$ predicted for the recipient in the HLT group and 109 (97.6 to 120$) \%$ predicted for the recipient in the BLT group. Despite the near normal TLC, residual volume (RV) and functional residual capacity (FRC) remained increased after transplantation in both groups. These abnormalities were not attributable to either airflow obstruction or expiratory muscle weakness. On average, lung compliance expressed in terms of the shape constant of the static pressure-volume curve of the lungs was mildly reduced in both groups compared with values predicted for the recipient.

Conclusions - These results suggest that at high lung volumes the chest wall adapts to the size of transplanted lungs, while at lower volumes the increase in FRC and RV might be due to a persistent change in the static pressure-volume curve of the chest wall.

(Thorax 1997;52:718-722)

Keywords: lung transplantation, lung compliance, pressure-volume curve, total lung capacity.

Bilateral lung and heart-lung transplantation are both used in the treatment of selected patients with various terminal lung diseases. Heart-lung transplantation (HLT) was the first procedure to be performed successfully ${ }^{1}$ but it has been partly displaced by the more frequently used bilateral lung transplantation (BLT) ${ }^{23}$ HLT continues to be the treatment of choice for patients with irreversible damage of both organs, whilst BLT is used mainly in patients with chronic septic lung conditions with reversible right ventricular dysfunction. Data on static lung volumes after HLT and BLT have been conflicting and there is very limited information on other aspects of respiratory mechanics after these procedures.

A restrictive defect has been described in the first 2-4 postoperative months after transplantation..$^{45}$ This has been attributed to the effects of the thoracotomy per $\mathrm{se}^{6}$ and it recovers by six months after transplantation. ${ }^{7}$

After HLT some groups have reported that total lung capacity (TLC) tends to recover towards the recipient's preoperative value, ${ }^{78}$ but others have reported values close to the predicted normal TLC, ${ }^{9}$ suggesting that the chest wall adapts to the transplanted lungs. After BLT the situation is potentially more complex as the chest wall has to adapt to two lungs anastomosed separately as well as to the effect of a bilateral thoracosternotomy or "clam shell incision". Although size matching of the lungs of the recipient and donor is attempted, there is inevitably some disparity between the size of the donor lungs, the size of the lungs removed, and the predicted normal capacity of the chest of the recipient.

In this study we have analysed dynamic and static lung volumes after HLT and BLT in order to assess the factors which determine lung volumes after transplantation. In particular we have compared the measured volumes after transplantation with the size of the recipient's lungs (which is influenced by the underlying disease), the predicted capacity of the thorax of the recipient, and the presumed (predicted) size of the transplanted (donor) lungs. We have further investigated respiratory mechanics after transplantation by measuring the static pressure-volume (PV) curves of the lungs and maximum respiratory pressures in patients after HLT and BLT.

Methods

Fifteen patients who received either HLT $(\mathrm{n}=$ 6) or BLT $(n=9)$ between August 1988 and November 1993 at the Cardiothoracic Centre, Freeman Hospital, Newcastle upon Tyne were investigated. Their demographic data are shown in table 1 . Only patients with no functional or histological evidence of obliterative bronchiolitis were selected for study. The surgical procedures have been described pre- 
Table 1 Mean (SE) characteristics of the patients and measurements of total lung capacity (TLC)

\begin{tabular}{|c|c|c|c|c|c|c|c|c|c|}
\hline \multirow{2}{*}{$\begin{array}{l}\text { Patient } \\
\text { no. }\end{array}$} & \multirow[t]{2}{*}{$\operatorname{Sex}$} & \multirow{2}{*}{$\begin{array}{l}\text { Age } \\
\text { (years) }\end{array}$} & & \multirow{2}{*}{$\begin{array}{l}\text { TLCdon } \\
\text { (litres) }\end{array}$} & \multirow{2}{*}{$\begin{array}{l}\text { TLCpred } \\
\text { (litres) }\end{array}$} & \multicolumn{2}{|l|}{ TLCpre } & \multicolumn{2}{|l|}{ TLCpost } \\
\hline & & & & & & Litres & $\%$ predicted & Litres & $\%$ predicted \\
\hline \multicolumn{10}{|c|}{ Heart-lung transplantation } \\
\hline 1 & $\mathrm{~F}$ & 30 & Eisenmenger's syndrome & 5.76 & 4.50 & 4.90 & 109 & 4.60 & 102 \\
\hline 2 & $\mathrm{M}$ & 29 & Cystic fibrosis & na & 6.45 & 8.40 & 130 & 7.40 & 115 \\
\hline 3 & $\mathrm{~F}$ & 32 & Bronchiectasis & 5.10 & 4.45 & 8.65 & 194 & 5.25 & 118 \\
\hline 4 & $\mathrm{M}$ & 33 & Eisenmenger's syndrome & 5.76 & 6.80 & 5.85 & 86 & 6.05 & 89 \\
\hline 5 & $\mathrm{~F}$ & 37 & Eisenmenger's syndrome & na & 4.80 & 5.15 & 107 & 4.50 & 94 \\
\hline 6 & $\mathrm{~F}$ & 37 & Primary pulm hypertension & na & 5.43 & 5.76 & 106 & 5.25 & 97 \\
\hline Mean & & 33.0 & & $5.5(0.2)$ & $5.4(0.4)$ & $6.50(0.7)$ & $122.0(15.5)$ & $5.50(0.4)$ & $102.5(4.8)$ \\
\hline \multicolumn{10}{|c|}{ Bilateral lung transplantation } \\
\hline 7 & $\mathrm{~F}$ & 47 & Bronchiectasis & 5.43 & 4.50 & 11.80 & 262 & 5.45 & 121 \\
\hline 8 & M & 22 & Cystic fibrosis & 6.90 & 6.35 & 5.10 & 80 & 6.55 & 103 \\
\hline 9 & M & 26 & Cystic fibrosis & 6.34 & 6.75 & 7.45 & 110 & 5.75 & 85 \\
\hline 10 & $\mathrm{M}$ & 33 & Eosinophilic granuloma & 6.75 & 6.25 & 7.35 & 118 & 5.95 & 95 \\
\hline 11 & $\mathrm{~F}$ & 30 & Cystic fibrosis & 5.86 & 4.85 & 6.55 & 135 & 4.75 & 98 \\
\hline 12 & $\mathrm{~F}$ & 18 & Cystic fibrosis & 4.77 & 4.65 & 5.20 & 112 & 5.80 & 125 \\
\hline 13 & $\mathrm{~F}$ & 22 & Cystic fibrosis & 5.43 & 5.25 & 5.05 & 96 & 5.90 & 112 \\
\hline 14 & $\mathrm{M}$ & 18 & Cystic fibrosis & 7.30 & 6.90 & 6.95 & 101 & 7.80 & 113 \\
\hline 15 & $\mathrm{~F}$ & 38 & Cystic fibrosis & 5.30 & 4.45 & 7.40 & 166 & 5.65 & 127 \\
\hline \multicolumn{2}{|c|}{ Mean (SE) } & 28.2 & & $6.0(0.3)$ & $5.6(0.3)$ & $7.0(0.7)$ & $131.1(18.3)$ & $6.0(0.3)$ & $108.8(4.8)$ \\
\hline
\end{tabular}

TLCdon $=$ assumed (i.e. predicted) donor TLC; TLCpred $=$ predicted recipient TLC; TLCpre $=$ measured recipient TLC before transplantation; TLCpost $=$ measured recipient TLC after transplantation; na = not available.

viously..$^{10}$ The study was approved by the local ethics committee and patients gave informed written consent.

Immunosuppressive treatment comprised cyclosporin A, sufficient to maintain a trough serum level of $350-450 \mathrm{ng} / \mathrm{ml}$ in the first six weeks after transplantation and 150-250 ng/ $\mathrm{ml}$ thereafter; prednisolone, initially $0.2 \mathrm{mg} / \mathrm{kg}$ daily and gradually tapering with the aim of discontinuing it one year after transplantation; and azathioprine, initially $1.5 \mathrm{mg} / \mathrm{kg}$ and adjusted to maintain the white blood count above $4.0 \times 10^{9}$ per litre.

FUNCTIONAL MEASUREMENTS

Preoperative lung volumes had been obtained within one year before the operation in 13 patients; in the other two patients they were measured 20 and 23 months preoperatively. Post-transplantation static lung volumes were measured in all patients at least six months after transplantation (mean 23 months, range 6-64) and at a time when the patients were free from acute complications.

Forced expiratory volume in one second $\left(\mathrm{FEV}_{1}\right)$ and vital capacity (VC) were obtained using either a dry wedge spirometer (Vitalograph Ltd, Buckingham, UK) or by integrating flow measured with a pneumotachograph (Flexiflo Model 407, PK Morgan Ltd, Gillingham, Kent, UK). Lung volumes were measured in a constant volume whole body plethysmograph (PK Morgan Ltd).

Pressure-volume (PV) curves were obtained using an oesophageal balloon as previously described $^{11}$ in a variable volume plethysmograph (J H Emerson, Model NM, Cambridge, Massachusetts, USA). The patients were asked to perform a sequence of three full inflations and the subsequent expiration was interrupted at the mouthpiece after successive small decrements in volume, at each of which static transpulmonary (mouth-oesophageal) pressure was measured. At least five manoeuvres were performed for each patient. Data were pooled and an exponential equation of the form $\mathrm{V}=\mathrm{Vmax}-\mathrm{Ae}^{-\mathrm{KP}}$ was fitted over the volume range from TLC to FRC; the shape constant $\mathrm{K}$ describes the elastic behaviour of the lungs over the whole volume range and is independent of lung size. ${ }^{12}$ Goodness of fit of the data was assessed visually and by calculation of $\mathrm{R}^{2}$. A curve was considered satisfactory provided that $R^{2}$ was $>0.90$ and the curve passed the $\operatorname{sign}^{13}$ and runs tests. ${ }^{14}$

Maximal inspiratory and expiratory pressures were measured at the mouth during forceful static efforts at FRC and TLC, respectively.

Predicted values for TLC, vital capacity (VC), residual volume (RV), functional residual capacity (FRC), and maximal respiratory pressures were calculated using standard equations based on sex, height, and age. ${ }^{1516}$ Predicted values for $\mathrm{K}$ were based on age. ${ }^{17}$

\section{ANALYSIS OF DATA}

Statistical analysis was performed using Minitab Statistical Software (Minitab Inc, State College, Pennsylvania, USA). Results are expressed as means (SE) and, where appropriate, 95\% confidence intervals are also shown. Comparisons between and within groups were made using non-parametric statistics (MannWhitney $U$ test). A p value of $<0.05$ was considered statistically significant.

The relationships between TLC after transplantation (TLCpost) and the three volumes defined above - namely, TLC of the recipient before transplantation (TLCpre), TLC predicted for the recipient (TLCpred), and TLC predicted for the donor (TLCdon) - were examined using univariate and multiple (stepwise) regression analysis. TLCdon was not obtainable for three of the patients in the HLT group because measurements of donor height were not available.

\section{Results}

LUNG VOLUMES

The individual and mean (SE) values of measured and predicted TLC for each group are shown in table 1. The mean TLCpre was greater than predicted in both groups and sig- 

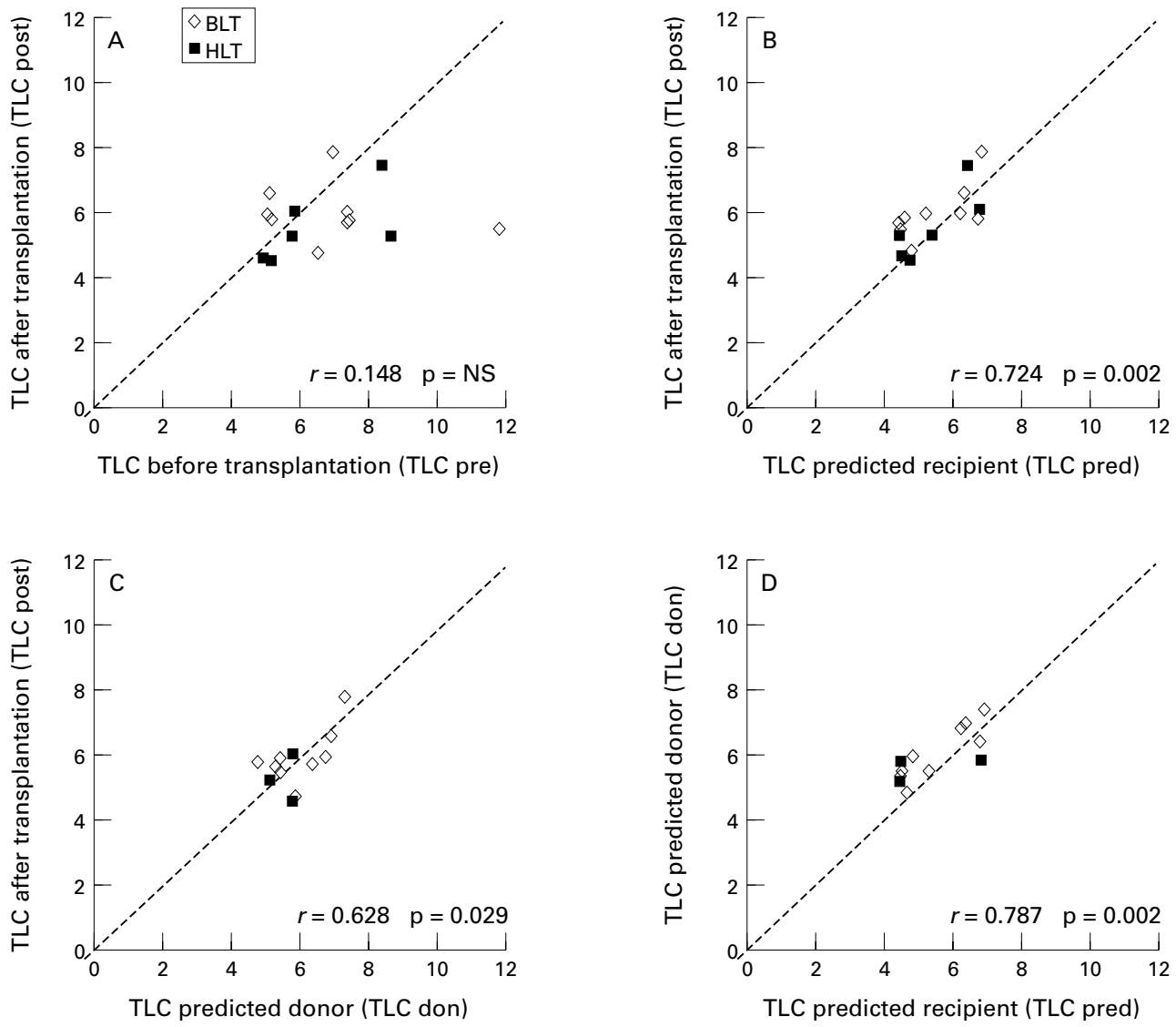

Figure 1 Correlations between TLCpost and (A) TLCpre, (B) TLCpred, and (C) TLCdon. In (D) the correlation between TLCpred and TLCdon is shown. Volume expressed in litres. Dotted line=line of identity.

nificantly so in patients who received a BLT (mean $131,95 \%$ CI 88.9 to $173 \%$ TLCpred, $\mathrm{p}=0.04)$. TLC returned to close to predicted values for the recipients in those who received a HLT (mean 103, 95\% CI 90.2 to $115 \%$ TLCpred) and remained slightly higher than predicted in the BLT group (mean 109, 95\% CI 97.6 to $120 \%$ TLCpred), although not significantly so (TLCpost vs TLCpred, $\mathrm{p}=$ NS). After transplantation patients who received a HLT showed a mean reduction in TLC of $19.5 \%$ of TLCpred (95\% CI -49.3 to 10.3) and patients who received a BLT showed a reduction of $22.3 \%$ TLCpred (95\% CI -61.3 to 16.6 ) but these changes were not statistically significant.

The estimated size of the transplanted lungs (TLCdon) was slightly bigger than the predicted volume for the recipient in both groups (mean 109\%) but the difference was not statistically significant.

The relations between TLCpost and TLCpre, TLCpred, and TLCdon for both groups together are shown in fig 1 together with the correlation between TLCpred and TLCdon. For both groups of patients together there was no significant correlation between TLCpre and TLCpost (fig 1A) but TLCpost showed a significant correlation with TLCpred (fig 1B). Although there was also a correlation between TLCpost and TLCdon (fig 1C), the influence of TLCdon became negligible when TLCpred was considered (stepwise re- gression). This is explained by the strong correlation between TLCpred and TLCdon (fig 1D). When the two groups of patients were considered separately in univariate analyses the conclusions in the patients who underwent BLT were similar to those in the whole population, with significant or borderline correlations between TLCpost and TLCpred ( $r=$ $0.68, \mathrm{p}=0.04)$, TLCpost and TLCdon $(r=$ $0.65, \mathrm{p}=0.056)$, and TLCdon and TLCpred $(r=0.89, \mathrm{p}<0.001)$ and no significant relation between TLCpost and TLCpre. In the (smaller) group of HLT patients alone the relations were not statistically significant although that between TLCpost and TLCpred approached significance $(r=0.80, \mathrm{p}=0.054)$.

Measurements of $\mathrm{FEV}_{1}$ and $\mathrm{VC}$ for both groups are summarised in table $2 . \mathrm{FEV}_{1}$ was more markedly reduced in the BLT group before transplantation. Each increased in both groups of patients after transplantation (fig 2) with larger and statistically significant increases in patients who received a BLT (mean increase of $\mathrm{FEV}_{1} 2.36$ (95\% CI 1.69 to 3.03) 1; FVC 2.24 (95\% CI 1.46 to 3.02 ) 1), corresponding with the lower pre-transplantation $\mathrm{FEV}_{1}$ and VC in the BLT group.

Before transplantation FRC and RV were higher than predicted in both groups (table 2). Whilst RV fell in both groups after transplantation (fig 2) with a greater reduction in the BLT group, the RV and FRC remained higher than predicted after transplantation in both groups. 


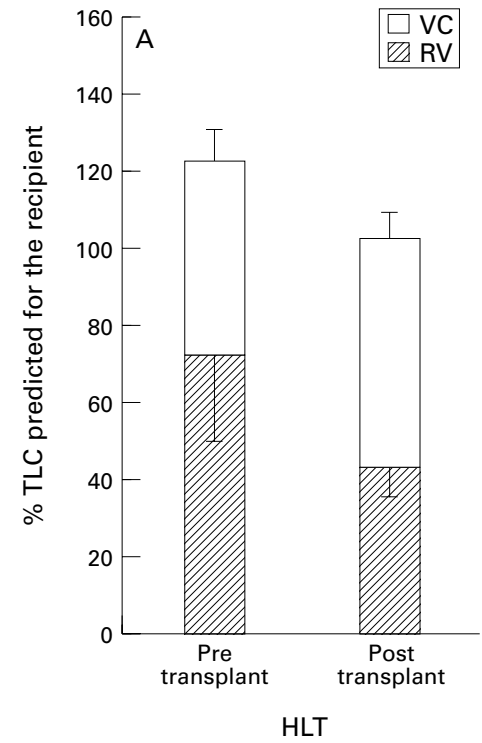

Figure 2 Mean (SE) vital capacity and residual volume before and after transplantation in patients undergoing $(A)$ heart-lung transplantation and $(B)$ bilateral lung transplantation expressed as \% of TLC predicted for the recipient.

\section{PV CURVES AND MAXIMUM RESPIRATORY PRESSURES}

PV curves and maximum respiratory pressures were obtained in nine patients after HLT $(\mathrm{n}=$ 4) and BLT $(n=5)$ (table 3). Goodness of fit of the PV data to the exponential equation was good for both groups (mean $\mathrm{R}^{2} 0.95$ (range $0.91-0.98)$ ) and all curves passed the runs and sign tests.

On average, lung compliance (expressed as $\mathrm{K})$ was slightly reduced in both groups in relation to values predicted for the recipient. Individual PV curves for all the patients are shown in fig 3. No consistent abnormalities were seen although, in general, patients with TLC higher than predicted showed curves to the left of the normal range and those with TLC lower than predicted were within or to the right of the normal values.

Both groups showed normal maximal respiratory pressures after transplantation. In six patients preoperative values were also available. Most showed improvement postoperatively, particularly in PImax. The improvement was more marked in the patients with the highest FRC before transplantation (patients 2 and 7).

\section{Discussion}

In general the results showed that, after HLT and BLT, TLC was close to the predicted value for the recipient. Since TLC was measured at least six months after transplantation, we did not observe the restrictive defect that has been described in similar patients in the first few months after transplantation.

Earlier reports ${ }^{78}$ suggested that patients recovered their pre-transplant TLC after HLT, but our results and those in one other series ${ }^{9}$ suggest that values are close to the predicted value for the recipient. Furthermore, our results suggest that a similar conclusion applies to patients after BLT. The correlations between post-transplantation TLC and the values predicted for the recipient, together with the lack of correlation with pre-transplantation TLC in both groups, suggest adaptation of the recipient's chest wall to the transplanted lungs.

Despite the return of TLC to a normal value, there was a consistent reduction in vital capacity (VC) with correspondingly raised RV and FRC. The cause of the persistent elevation of

Table 2 Mean (SE) pulmonary function data before and after transplantation expressed in litres and as \% predicted for the recipient.

\begin{tabular}{|c|c|c|c|c|c|c|c|c|}
\hline & \multicolumn{2}{|l|}{$F E V_{1}$} & \multicolumn{2}{|l|}{$V C$} & \multicolumn{2}{|l|}{$R V$} & \multicolumn{2}{|l|}{$F R C$} \\
\hline & Pre & Post & Pre & Post & Pre & Post & Pre & Post \\
\hline \multicolumn{9}{|l|}{ HLT $(n=6)$} \\
\hline litres & $1.8(0.4)$ & $2.8(0.4)$ & $2.7(0.4)$ & $3.3(0.5)$ & $3.8(1.1)$ & $2.3(0.4)$ & $4.7(0.9)$ & $3.7(0.4)$ \\
\hline $\begin{array}{l}\% \text { predicted for } \\
\text { recipient }\end{array}$ & $58.0(14.2)$ & $84.6(9.4)$ & $70.3(12.3)$ & $82.3(8.2)$ & $257.2(80.1)$ & $152.8(26.8) \Phi$ & $166.1(33.5)$ & $132.8(10.9)^{* *}$ \\
\hline \multicolumn{9}{|l|}{$\operatorname{BLT}(\mathrm{n}=9)$} \\
\hline litres & $0.8(0.3)^{*}$ & $3.2(0.2)^{*}$ & $1.5(0.3)^{*}$ & $3.8(0.2)^{*}$ & $5.4(0.8) \dagger$ & $2.2(0.2) \dagger$ & $5.8(0.7) \ddagger$ & $4.0(0.2) \ddagger$ \\
\hline $\begin{array}{l}\text { \%predicted for } \\
\text { recipient }\end{array}$ & $23.8(6.8)$ & $93.6(6.0)$ & $37.6(6.2)$ & $93.3(6.9)$ & $381.1(50.1)$ & $152.6(14.6) \|$ & $204.3(26.8)$ & $139.4(6.8)^{* * * *}$ \\
\hline
\end{tabular}

$\mathrm{FEV}_{1}=$ forced expiratory volume in one second; $\mathrm{VC}=$ vital capacity; $\mathrm{RV}=$ residual volume; $\mathrm{FRC}=$ functional residual capacity.

$* \mathrm{p}=0.001, \dagger \mathrm{p}=0.0004, \ddagger \mathrm{p}=0.01$ pre vs post-transplantation.



Table 3 Lung compliance $(K)$ after transplantation expressed per $\mathrm{cm} \mathrm{H}_{2} \mathrm{O}$ and as percentage predicted for the recipient and for the donor and maximum inspiratory and expiratory pressures (PImax, PEmax) before and after transplantation in $\mathrm{cm} \mathrm{H}_{2} \mathrm{O}$ (\% predicted)

\begin{tabular}{|c|c|c|c|c|c|c|c|}
\hline \multirow{2}{*}{$\begin{array}{l}\text { Patient } \\
\text { no. }\end{array}$} & \multirow{2}{*}{$\begin{array}{l}\mathrm{K} \\
\left(\mathrm{lcm} \mathrm{H}_{2} \mathrm{O}\right)\end{array}$} & \multirow{2}{*}{$\begin{array}{l}K \\
\text { (\% predicted } \\
\text { recipient })\end{array}$} & \multirow{2}{*}{$\begin{array}{l}K \\
\text { (\% predicted } \\
\text { donor) }\end{array}$} & \multicolumn{2}{|l|}{ PImax } & \multicolumn{2}{|l|}{ PEmax } \\
\hline & & & & $\begin{array}{l}\text { Pre } \\
\text { (cm } \mathrm{H}_{2} \mathrm{O} \text { (\%pred)) }\end{array}$ & $\begin{array}{l}\text { Post } \\
\text { (cm } \mathrm{H}_{2} \mathrm{O} \text { (\%pred)) }\end{array}$ & $\begin{array}{l}\text { Pre } \\
\text { (cm } \mathrm{H}_{2} \mathrm{O}(\% \text { pred)) }\end{array}$ & $\begin{array}{l}\text { Post } \\
\text { (cm } \mathrm{H}_{2} \mathrm{O} \text { (\%pred)) }\end{array}$ \\
\hline \multicolumn{8}{|c|}{ Heart-lung transplantation } \\
\hline 2 & 0.127 & 98 & 96 & $45(42)$ & $155(145)$ & $100(67)$ & $150(100)$ \\
\hline 4 & 0.090 & 69 & 80 & $80(76)$ & $100(95)$ & $140(95)$ & $95(65)$ \\
\hline 5 & 0.110 & 82 & 101 & na & $80(113)$ & na & $120(131)$ \\
\hline 6 & 0.118 & 90 & 105 & na & $45(58)$ & na & $78(80)$ \\
\hline Mean & 0.111 & 84.8 & 95.7 & $63(59)$ & $95(103)$ & $120(81)$ & $111(94)$ \\
\hline \multicolumn{8}{|c|}{ Bilateral lung transplantation } \\
\hline 7 & 0.094 & 67 & 74 & $15(20)$ & $80(105)$ & $70(73)$ & $140(146)$ \\
\hline 10 & 0.063 & 49 & 53 & $120(112)$ & $170(159)$ & $198(132)$ & $176(118)$ \\
\hline 11 & 0.104 & 83 & 88 & na & $80(112)$ & na & $70(76)$ \\
\hline 12 & 0.093 & 82 & 73 & $54(78)$ & $80(115)$ & $98(108)$ & $76(84)$ \\
\hline 13 & 0.099 & 84 & 73 & $72(95)$ & $80(105)$ & $86(90)$ & $110(115)$ \\
\hline Mean & 0.091 & 72.7 & 72.2 & $65(76)$ & $98(120)$ & $113(101)$ & $114(108)$ \\
\hline
\end{tabular}



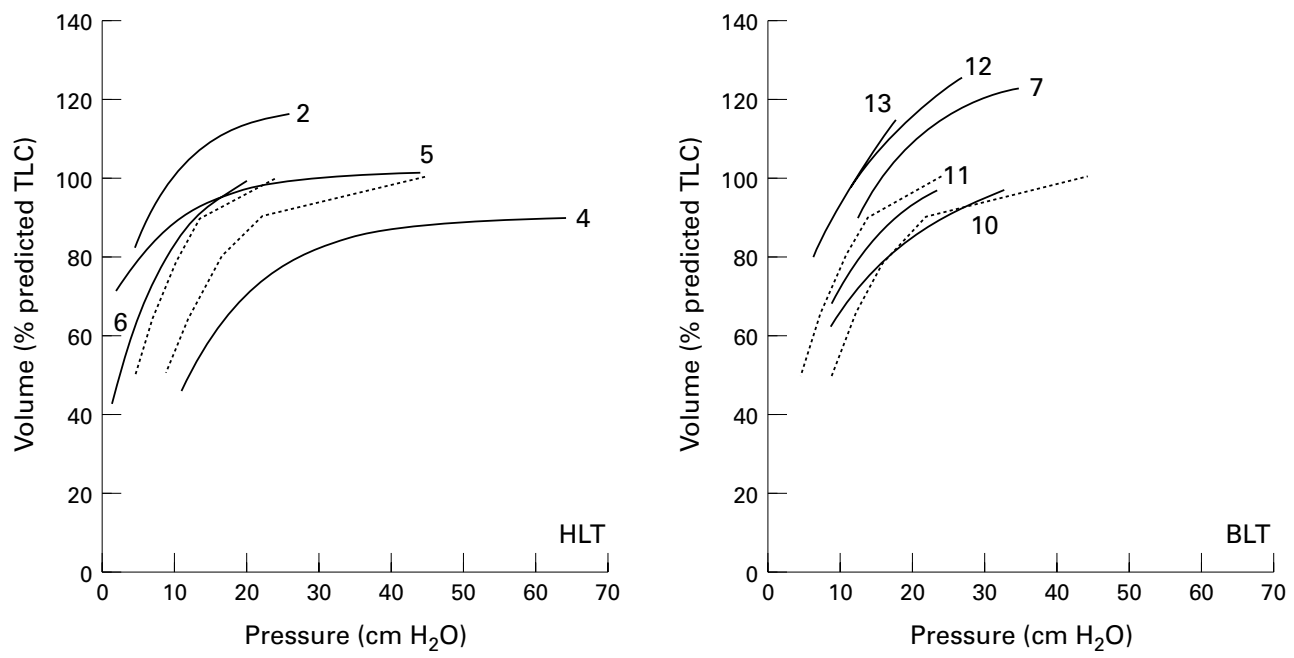

Figure 3 Pressure-volume curves for each individual case expressed with volume as \% of predicted for the recipient. Dotted lines $=$ predicted normal range. ${ }^{18}$

$\mathrm{RV}$ and $\mathrm{FRC}$ is unclear. The $\mathrm{FEV}_{1} / \mathrm{VC}$ ratio was normal after transplantation in both groups, suggesting that airway obstruction is unlikely to be the explanation, nor was there evidence of expiratory muscle weakness. Our results of lung distensibility in the HLT group (96\% predicted for the recipient and $85 \%$ predicted for the donor) are similar to those in a previous report of 12 patients after HLT $(\mathrm{K}=91 \%$ of predicted for the donor and $86 \%$ of predicted for the recipient ${ }^{19}$ ), and suggest virtually normal elastic behaviour of the transplanted lungs. In view of the thoracic hyperinflation of most of the patients before transplantation, it is possible that irreversible changes in the static elastic properties of the chest wall account for the persistently raised FRC and RV. A permanent displacement of the static chest wall PV curve to higher volumes with consequent resetting of the balance between the inward recoil of the lungs and an increased outward recoil of the chest wall would produce such an increased FRC and also limit maximum expiration with a consequent increase in RV. However, no information is available on the passive elastic properties of the chest wall of patients after transplantation.

It may be relevant that seven of the nine patients in the BLT group had cystic fibrosis, as a recent study in patients with cystic fibrosis showed a similar pattern with normal TLC and persistently raised FRC after heart-lung transplantation. ${ }^{20}$ The authors attributed these findings to a structural adaptation acquired during growth of the rib cage. ${ }^{20}$

Our results suggest therefore that, after BLT or HLT, the chest wall adapts well to the transplanted lungs at high volumes resulting in TLC values which are close to normal, while at lower volumes permanent distortions of the chest wall acquired before transplantation may remain and prevent complete expiration, thus elevating FRC and RV.

The authors thank Mr T N Stone for technical assistance. RAC was in receipt of a training fellowship from the Overseas
Development Administration of the British Government (British Council) in cooperation with the Costa Rican Government.

1 Reitz BA, Wallwork JL, Hunt SA, Pennock JL, Billingham ME, Oyer PE, et al. Heart-lung transplantation. Successful therapy for patients with pulmonary vascular disease. $N$ Engl f Med 1982;306:557-64.

2 Kaiser LR, Pasque MK, Trulock EP, Low DE, Dresler CM Cooper JD. Bilateral sequential lung transplantation: the procedure of choice for double-lung replacement. Ann Thorac Surg 1991;52:438-46.

3 Cooper JD, Patterson GA, Grossman R, Maurer J, and the Toronto Lung Transplant Group. Double lung transplant for advanced chronic obstructive lung disease. Am Rev Respir Dis 1989;139:303-7.

4 Griffith BP, Hardesty RL, Trento A, Paradis IL, Duquesnoy RJ, Zeevi A, et al. Heart-lung transplantation: lessons Rearned and future hopes. Amn I

5 Burke CM, Theodore J, Baldwin JC, Tazelaar HD, Morris AJ, McGregor C, et al. Twenty eight cases of human heart-lung transplantation. Lancet 1986;i:517-9.

6 Theodore J, Jamieson SW, Burke CM, Reitz BA, Stinson EB, Van Kessel A, et al. Physiologic aspects of human EB, Van Kessel A, et al. Physiologic aspects of hun

7 Lloyd KS, Barnard P, Holland VA, Noon GP, Lawrence EC. Pulmonary function after heart-lung transplantation using larger donor lungs. Am Rev Respir Dis 1990;142 $1026-9$.

8 Otulana BA, Mist BA, Scott JP, Wallwork J, Higenbottam $\mathrm{T}$. The effect of recipient lung size on lung physiology after heart-lung transplantation. Transplantation 1989;48: 625-9.

9 Tamm M, Higenbottam TW, Dennis CM, Sharples LD, Wallwork J. Donor and recipient predicted lung volume and lung size after heart-lung transplantation. Am $\mathcal{F}$ Respir Crit Care Med 1994;150:403-7.

10 Kirk AJB, Richens D, Dark JH. A manual of cardiopulmonary transplantation. 1st ed. Kent: Hodder and Stoughton, 1993: 50-3.

11 Gibson GJ, Pride NB. Lung distensibility. The static pressure-volume curve of the lungs and its use in clinical assessment. Brf Dis Chest 1976;70:143-84.

12 Gibson GJ, Pride NB, Davis J, Schroter RC. Exponential description of the static pressure-volume curve of normal and diseased lungs. Am Rev Respir Dis 1979;120:799-811.

13 Armitage P, Berry G. Statistical methods in medical research 2nd ed. Blackwell Scientific Publications, 1987.

14 Draper NR, Smith H. Applied regression analysis. New York. John Wiley and Sons, 1966

15 European Community for Steel and Coal. Standardized lung function testing. Eur Respir f 1993;6(Suppl 16).

16 Wilson SH, Cooke NT, Edwards RHT, Spiro SG. Predicted normal values for maximal respiratory pressures in caucasian adults and children. Thorax 1984;39:535-8.

17 Colebatch HJH, Greaves IA, Ng CKY. Exponential analysis of elastic recoil and a ing in healthy males and females. f Appl Physiol 1979;47:683-91.

18 Knudson RJ, Clark DF, Kennedy TC, Knudson DE. Effect of aging alone on mechanical properties of the normal of aging alone on mechanical properties of the nor

19 Glanville AR, Theodore J, Harvey J, Robin ED. Elastic behaviour of the transplanted lung. Exponential analysis of static pressure-volume relationships. Am Rev Respir Di

20 Guignon I, Cassart M, Gevenois PA, Knoop C, Antoine M, Yernault JC, et al. Persistent hyperinflation after heart-lung transplantation for cystic fibrosis. Am $\mathcal{F}$ Respir Crit Car Med 1995;151:534-40. 